\title{
Recommendations of the Colombian Consensus Committee for the Management of Traumatic Brain Injury in Prehospital, Emergency Department, Surgery, and Intensive Care (Beyond One Option for Treatment of Traumatic Brain Injury: A Stratified Protocol [BOOTStraP])
}

\author{
Andres M. Rubiano ${ }^{1}$ David S. Vera ${ }^{2} \quad$ Jorge H. Montenegro ${ }^{3}$ Nancy Carney $^{4}$ Angelica Clavijo $^{5}$ \\ Jose N. Carreño Oscar Gutierrez $^{7}$ Jorge Mejia ${ }^{8} \quad$ Juan D. Ciro ${ }^{9} \quad$ Ninel D. Barrios ${ }^{10}$ Alvaro R. Soto ${ }^{11}$ \\ Paola A. Tejada ${ }^{12}$ Maria C. Zerpa ${ }^{13} \quad$ Alejandro Gomez ${ }^{14} \quad$ Norberto Navarrete $^{15} \quad$ Oscar Echeverry ${ }^{16}$ \\ Mauricio Umaña ${ }^{17}$ Claudia M. Restrepo ${ }^{18} \quad$ Jose L. Castillo ${ }^{19}$ Oscar A. Sanabria ${ }^{20}$ Maria P. Bravo ${ }^{21}$ \\ Claudia M. Gomez ${ }^{22}$ Daniel A. Godoy ${ }^{23}$ German D. Orjuela ${ }^{24}$ Augusto A. Arias ${ }^{25}$ \\ Raul A. Echeverri26 Jorge Paranos ${ }^{27}$
}

\footnotetext{
${ }^{1}$ NIHR Global Health Research Group in Neurotrauma, University of Cambridge, UK/Neurosciences Institute, Universidad El Bosque, Bogotá, Colombia/Meditech Foundation, Cali, Colombia

${ }^{2}$ MEDITECH Foundation, Universidad El Bosque, Bogota, Colombia

${ }^{3}$ Emergency Service, Local Hospital of Puerto Asís, Putumayo, Colombia

${ }^{4}$ School of Medicine, Oregon Health \& Science University, Portland,

Oregon, United States

5INUB MEDITECH, Universidad El Bosque, Clinical Research, Bogotá, Colombia

6Department of Intensive Care, Fundación Santa Fé University Hospital, Bogotá, Colombia

${ }^{7}$ Neurosurgery Service, Hospital Occidente de Kennedy, Bogotá, Colombia

${ }^{8}$ Department of Intensive Care, Valle de Lili Foundation, Cali, Colombia

${ }^{9}$ Intensive Care Service, Las Américas Clinic, Medellín, Colombia

10 Intensive Care Service, Clínica General del Norte, Barranquilla,

Colombia

${ }^{11}$ Neurosurgery Service, San Antonio Departamental Hospital, Pitalito-Huila, Colombia

12 Institute of Neurosciences, Universidad El Bosque, Clinical Research, Bogotá, Colombia

${ }^{13}$ Intensive Care Service, Clínica Del Norte, Cúcuta, Colombia

${ }^{14}$ Prehospital Care Program, Adventist University, Medellín, Colombia

15Burns Unit, Simón Bolívar Hospital, Bogotá, Colombia

${ }^{16}$ Clinical Research, MEDITECH Foundation, Cali, Colombia

${ }^{17}$ Intensive Care Service, Clinica Amiga, Cali, Colombia

18 Neurosurgery Service, Hospital Militar Central, Bogota, Colombia

${ }^{19}$ Intensive Care Service, Vallesalud Clinic, Cali, Colombia

${ }^{20}$ Faculty of Medicine, Universidad El Bosque, Bogotá, Colombia

${ }^{21}$ Faculty of Medicine, Universidad Surcolombiana, Neiva, Colombia

${ }^{22}$ Neurosurgery Service, Urabá Clinic, Apartadó-Antioquia, Colombia

${ }^{23}$ Intensive Care Service, Sanatorium Pasteur, Catamarca, Argentina

${ }^{24}$ Prehospital Care Program, Secretary of Health, Bogotá, Colombia

25 Intensive Care Service, Clínica del Norte, Cúcuta, Colombia

${ }^{26}$ Neurosurgery Service, Vallesalud Clinic, Cali, Colombia

${ }^{27}$ Neurosurgery and Intensive Care Service, Santa Casa da Misericórdia Hospital in São João del-Rei, São João del-Rei, Minas Gerais, Brazil
}

J Neurosci Rural Pract 2020;11:7-22
Address for correspondence Andres M. Rubiano, MD, PhD, Department of Neurosciences and Neurosurgery, El Bosque University, Bogotá, Colombia; Medical and Research Director MEDITECH Foundation, MEDITECH Foundation, Calle 7-A \# 44-95, Cali, Valle, Colombia (e-mail: andresrubiano@aol.com).
(C)2020 Association for Helping Neurosurgical Sick People

License terms

$10.1055 / \mathrm{s}-0040-1701370$

ISSN 0976-3147. 
Abstract

\section{Keywords}

- traumatic brain injuries

- intensive care

- emergency care

- prehospital care

- critical care

- intensive care

- Colombia

- guideline
Background Traumatic brain injury (TBI) is a global public health problem. In Colombia, it is estimated that $70 \%$ of deaths from violence and $90 \%$ of deaths from road traffic accidents are TBI related. In the year 2014, the Ministry of Health of Colombia funded the development of a clinical practice guideline (CPG) for the diagnosis and treatment of adult patients with severe TBI. A critical barrier to the widespread implementation was identified-that is, the lack of a specific protocol that spans various levels of resources and complexity across the four treatment phases. The objective of this article is to present the process and recommendations for the management of patients with TBI in various resource environments, across the treatment phases of prehospital care, emergency department (ED), surgery, and intensive care unit.

Methods Using the Delphi methodology, a consensus of 20 experts in emergency medicine, neurosurgery, prehospital care, and intensive care nationwide developed recommendations based on 13 questions for the management of patients with TBI in Colombia.

Discussion It is estimated that $80 \%$ of the global population live in developing economies where access to resources required for optimum treatment is limited. There is limitation for applications of CPGs recommendations in areas where there is low availability or absence of resources for integral care. Development of mixed methods consensus, including evidence review and expertise points of good clinical practices can fill gaps in application of CPGs. BOOTStraP (Beyond One Option for Treatment of Traumatic Brain Injury: A Stratified Protocol) is intended to be a practical handbook for care providers to use to treat TBI patients with whatever resources are available.

Results Stratification of recommendations for interventions according to the availability of the resources on different stages of integral care is a proposed method for filling gaps in actual evidence, to organize a better strategy for interventions in different real-life scenarios. We develop 10 algorithms of management for building TBI protocols based on expert consensus to articulate treatment options in prehospital care, EDs, neurological surgery, and intensive care, independent of the level of availability of resources for care.

\section{Introduction}

Traumatic brain injury (TBI) is a global public health problem. ${ }^{1}$ The World Health Organization (WHO) estimates that by the year 2020, TBI will be one of the leading causes of death and disability globally. ${ }^{1}$ Approximately $1,250,000$ people die each year as a result of road traffic accidents (RTAs). ${ }^{1,2}$ TBIs affect more than 10,000,000 people annually and are the leading cause of death among persons between 15 and 29 years of age. ${ }^{1,2}$

Epidemiological studies show regional variations, with higher mortality in patients from rural areas and low- and middle-income countries (LMICs), in comparison with urban areas of high-income countries (HICs)., ${ }^{3,4}$ This higher mortality and disability associated with TBI in the areas of lower income groups are associated with the lack of prevention, less control of risk factors, and lower capacity for acute care and rehabilitation. ${ }^{5}$ The WHO Global Report of Road Safety for the year 2015 states that $90 \%$ of deaths from RTAs occurs in LMICs. ${ }^{6}$ However, while LMICs account for $82 \%$ of the world's population, only $54 \%$ of the world's registered vehicles are in LMICs, indicating a disproportionate number of road traffic deaths. ${ }^{6}$ Colombia is a country that still maintains a high incidence of trauma from social violence and traffic accidents. ${ }^{7}$ Of these traumas, the estimates associated with TBI range from 49 to $70 \%{ }^{7}$ There is little accurate information in Colombia about the deaths attributed to TBI. However, estimates from autopsy reports of the National Institute of Legal Medicine and Forensic Sciences indicate that 70\% of deaths from violence and $90 \%$ of deaths from RTAs are TBI related. ${ }^{7}$

In the year 2014, the Ministry of Health of Colombia, through the convocation 563-2012 of the Administrative Department of Science, Technology and Information (COLCIENCIAS), funded the development of a clinical practice guideline (CPG) for the diagnosis and treatment of adult patients (older than 15 years) with severe TBI. ${ }^{8}$ This guideline was developed under the direction of the Meditech Foundation, utilizing expert clinical representatives from multiple disciplines involved in the comprehensive care of TBI patients. The document, including recommendations based on scientific evidence, is intended to decrease the heterogeneity in the management of these patients across the four treatment phases of prehospital care, emergency department (ED) management, surgery, and intensive care 
unit (ICU) (please refer http://gpc.minsalud.gov.co/gpc_sites/ Repositorio/Conv_563/GPC_trauma_craneo/CPG_TBI_professionals.pdf). Two years after its publication as a technical paper of the Ministry of Health, there were various meetings to advance implementation. During this process, an essential barrier to the widespread implementation was identifiedthat is, the lack of a specific protocol that spans various levels of resources and complexity across the four treatment phases.

Based on the current required regulations for enabling health services in Colombia, where complexity levels are described as shown in - Table 1, a consensus process involving clinical experts was conducted to develop a series of management protocols to articulate treatment options for
TBI specific to different levels of resources and complexity across the prehospital, emergency care, neurological surgery, and intensive care phases. The expert panel included representatives from the Colombian Association of Universities with programs in Prehospital Care, the Colombian Association of Specialists in Emergency Medicine, the Colombian Association of Neurosurgery, Chapter of Neurotrauma, and the Colombian Association of Critical Care Medicine and Intensive Care through the Chapter of Neurointensive Care. The objective of this article is to present the process and recommendations for the management of patients with TBI in various resource environments, across the treatment phases of prehospital care, ED, neurosurgery (NSG), and ICU.

Table 1 Definitions of levels of complexity of prehospital, emergency care, surgery, and intensive care

\begin{tabular}{|c|c|c|c|c|c|c|c|}
\hline \multicolumn{8}{|c|}{ Level of resource definitions } \\
\hline \multicolumn{2}{|c|}{ Ambulances } & \multicolumn{2}{|c|}{ Emergency room } & \multicolumn{2}{|c|}{ Neurological surgery } & \multicolumn{2}{|c|}{ ICU } \\
\hline $\begin{array}{l}\text { Basic } \\
\text { emergency } \\
\text { transport }\end{array}$ & $\begin{array}{l}\text { Advanced } \\
\text { emergency } \\
\text { transport }\end{array}$ & $\begin{array}{l}\text { Basic health } \\
\text { facility } \\
\text { (without CT) } \\
\text { Low } \\
\text { complexity }\end{array}$ & $\begin{array}{l}\text { Advanced health } \\
\text { facility (with CT) } \\
\text { Medium-high } \\
\text { complexity }\end{array}$ & $\begin{array}{l}\text { Operation } \\
\text { room with } \\
\text { CT access } \\
\text { but without } \\
\text { neurosurgery }\end{array}$ & $\begin{array}{l}\text { Operation } \\
\text { room with } \\
\text { neurosurgery, } \\
\text { but without } \\
\text { ICU availability }\end{array}$ & $\begin{array}{l}\text { ICU with } \\
\mathrm{CT} \text {, center } \\
\text { of medium } \\
\text { complexity }\end{array}$ & $\begin{array}{l}\text { ICU with CT, } \\
\text { in a center of } \\
\text { medium-high } \\
\text { complexity }\end{array}$ \\
\hline $\begin{array}{l}\text { - Vehicle } \\
\text { with first } \\
\text { responder } \\
\text { (with or } \\
\text { without } \\
\text { training) } \\
\text { - Vehicle } \\
\text { with or } \\
\text { without } \\
\text { electronic } \\
\text { monitor- } \\
\text { ing of vital } \\
\text { signs } \\
\text { - Vehicle } \\
\text { without } \\
\text { advanced } \\
\text { airway } \\
\text { manage- } \\
\text { ment } \\
\text { equipment } \\
\text { - Vehicle } \\
\text { with or } \\
\text { without } \\
\text { IV fluids } \\
\text { capability }\end{array}$ & $\begin{array}{l}\text { Vehicle with: } \\
\text { - } \text { Physician, } \\
\text { nurse, } \\
\text { technician, } \\
\text { or technical } \\
\text { EMS sup- } \\
\text { port } \\
\text { - } \\
\text { Driver with } \\
\text { training in } \\
\text { basic life } \\
\text { support } \\
\text { - } \text { Mechanical } \\
\text { ventilator } \\
\text { with bat- } \\
\text { tery for at } \\
\text { least } 4 \mathrm{~h} \\
\text { - Electronic } \\
\text { monitoring } \\
\text { of vital } \\
\text { signs } \\
\text { - } \text { AED } \\
\text { - } \text { Advanced } \\
\text { airway } \\
\text { manage- } \\
\text { ment kit } \\
\text { - Medica- } \\
\text { tions for } \\
\text { advanced } \\
\text { life support }\end{array}$ & 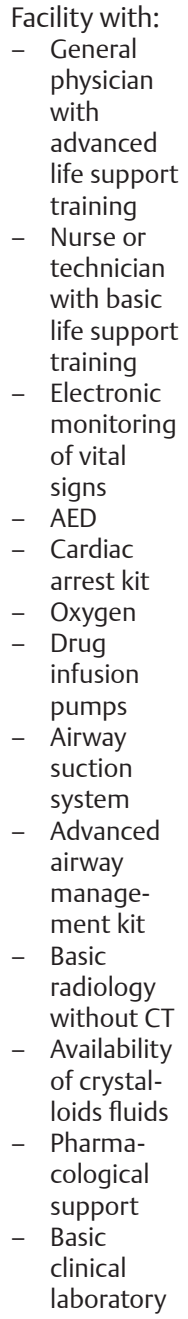 & $\begin{array}{l}\text { Facility with: } \\
\text { - General } \\
\text { physician, } \\
\text { emergency } \\
\text { specialist, or } \\
\text { family physician } \\
\text { - } \\
\text { Specialist avail- } \\
\text { ability in basic } \\
\text { consultancy } \\
\text { (general sur- } \\
\text { gery/internal } \\
\text { medicine/pedi- } \\
\text { atrics) } \\
\text { - Clinical labo- } \\
\text { ratory } \\
\text { - } \text { Radiology ser- } \\
\text { vice (with CT) } \\
\text { - Pharmacy } \\
\text { - } \text { Respiratory } \\
\text { therapy } \\
\text { - Blood transfu- } \\
\text { sion kit } \\
\text { - Health care } \\
\text { transport } \\
\text { - Operating } \\
\text { room with } \\
\text { anesthesiology } \\
\text { available }\end{array}$ & $\begin{array}{ll}\text { Facility with: } \\
\text { - } & \text { General } \\
& \text { surgeon } \\
\text { - } & \text { Anesthesi- } \\
& \text { ologist } \\
\text { - } & \text { Operative } \\
& \text { room } \\
& \text { available } \\
\text { - } & \text { Surgical } \\
& \text { instrumen- } \\
& \text { tation } \\
\text { - } & \text { Surgical } \\
& \text { nurses } \\
\text { - } & \text { Clinical } \\
& \text { laboratory } \\
\text { - } & \text { Pharmacy } \\
\text { - } & \text { Basic } \\
& \text { surgical } \\
& \text { equipment } \\
\text { - } & \text { Facility } \\
& \text { without } \\
& \text { neuro- } \\
& \text { surgery } \\
\text { availability }\end{array}$ & 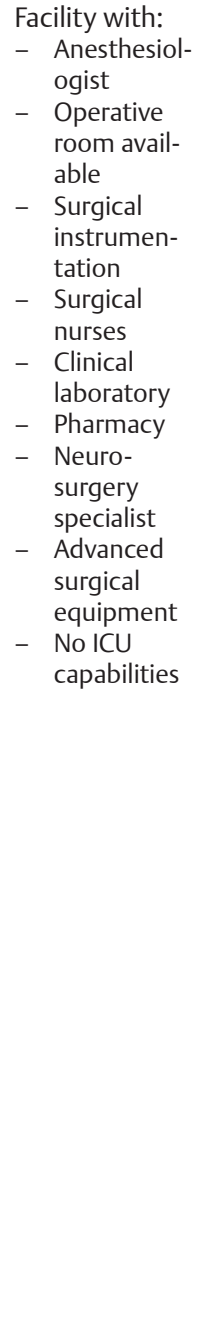 & 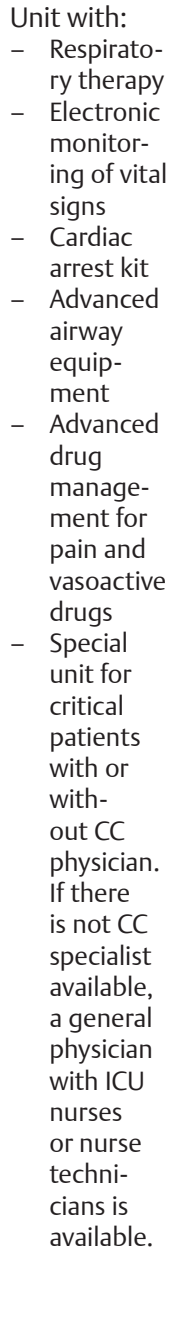 & 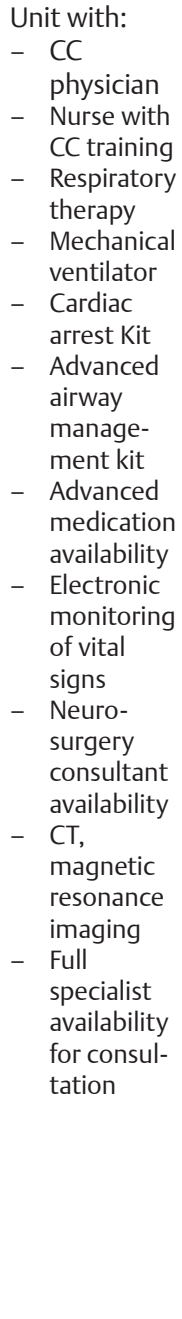 \\
\hline
\end{tabular}




\section{Materials and Methods}

In March 2017, a national consensus conference for the development of the protocol for comprehensive care of adults with TBI was held in Bogota, Colombia. Twenty experts in prehospital care, emergency medicine, neurosurgery, and intensive care attended, accompanied by five methodologists. Six participants attended through videoconferencing and 19 in person. The process took 3 days; 2 meeting days with 1 final consensus day during which participants discussed possible answers to the following questions.

\section{Prehospital Care}

What is the best protocol (step by step) for treating an adult patient:

1. Mild TBI in a basic ambulance or basic emergency transport (BET)?

2. Moderate-severe TBI in a BET?

3. Mild TBI in a medical ambulance or advanced emergency transport (AET)?

4. Moderate-severe TBI in an AET?

\section{Emergency Care}

What is the best protocol (step by step) for managing an adult patient with:

5. Mild TBI in a low complexity ED without computed tomography $(\mathrm{CT})$ ?

6. Mild TBI in a medium-high complexity ED with CT?

7. Moderate-severe TBI in a low complexity ED without CT?

8. Moderate-severe TBI in a medium-high complexity ED with CT?

\section{Neurological Surgery}

9. What is the best protocol to determine if a patient with TBI requires immediate neurological surgery?

What is the best protocol to manage a patient who requires immediate surgery in a medical center that:Does it not have neurosurgery?

10. Does it not have neurosurgery?

11. Have neurosurgery but no ICU?

\section{Intensive Care}

12. What is the best protocol to manage a patient with moderate-severe TBI in an intermediate care unit (no ICU) within a center of medium complexity?

13. What is the best protocol to manage a patient with moderate-severe TBI in an ICU within a center of medium-high complexity?

We conducted a systematic search for publications that described methods for conducting consensus processes when evidence alone was insufficient to establish protocols. One publication described the use of the Delphi method combined with the nominal group method to achieve consensus in developing guidelines for the management of severe sepsis and septic shock. ${ }^{11}$ In this document, investigators provided specific information about the iterative process they used to funnel disparate opinions into a manageable set of questions, and about how they quantified the convergence of opinions. The process developed for this project is a modification of the one used for the sepsis guidelines. ${ }^{11}$ We used the principles and practices of the Delphi method ${ }^{12}$ and Nominal Group Method $^{13}$ to conduct this project.

Participants were organized into subgroups of prehospital care, emergency medicine, neurosurgery, and intensive care, according to their expertise and background with a moderator for each subgroup. A month in advance of the meeting, each subgroup was provided with preparation material, which included the scientific evidence on specific interventions for each area, as well as CPGs-those based on evidence and those based on expert consensus. ${ }^{14-35}$ The questions were allocated to each subgroup, and in the first session (day 1 ), through a series of voting rounds, an agreement was reached among the subgroups. A 70\% agreement rate was required to specify each recommendation. Next, a representative of each subgroup presented its recommendations to the entire group, which discussed the recommendations considering the scientific evidence and expert opinion. The entire group then voted on each recommendation and continued this iterative process of discussion and voting until a $90 \%$ agreement rate was obtained to endorse a recommendation. Facilitators of the methodological team support the discussion and voting sessions all the time.

In the final session, management algorithms were presented, which integrated the recommendations, adjusted, and stratified according to the availability of resources in centers of varying complexity. The product was named as BOOTStraP-Beyond One Option for Treatment of Traumatic Brain Injury: A Stratified Protocol (-Supplementary Material S1 [online only]).

\section{Results}

How to Interpret and Use the Proposed Algorithms

We have created categories for each treatment phase, according to real scenarios presented by experts from different regions of the country, and identified in different surveys ${ }^{36,37}$ during the development of the Colombian TBI guidelines.

- Prehospital: Basic ambulance or BET; medical ambulance or AET.

- Emergency care: Low complexity (without CT), medium-high complexity with CT.

- Neurological surgery: Does not have neurosurgery available; has neurosurgery but no ICU availability.

- Intensive care: Has an intermediate care unit but no ICU availability and no neurosurgery availability; has ICU and neurosurgery availability.

Therefore, the algorithms for treatment shown later are not organized according to strict categorizations. They are 
stratified. In this way, a medical provider in any of the four treatment phases can select the best practice treatment option, depending on the available resources as shown in -Fig. 1. The treatment options in the algorithms below are presented in red, yellow, or green background. A red background indicates the proposed intervention can be performed in the lowest level of resources; a yellow background indicates the intervention can be performed at a medium level of resources, and green background indicates the interventions are regularly performed in the most advanced level of resources. All the options (proposed interventions) can be selected from the algorithms and organized in different levels of care according to the availability of the mentioned resources.

\section{Questions 1 and 2}

What is the best protocol for treating an adult patient with mild, moderate, or severe TBI in a BET?

\section{Recommendation}

- It is recommended that the management of adult patients who present with mild TBI (without criteria for prehospital care or transfer in an AET) can be performed in a BET. However, if the planned transfer is longer than 30 minutes, and AET should be requested if available.

- It is recommended that no patient with moderate or severe TBI be transported in a BET, but if this situation occurs in any region, algorithm in -Fig. 2 should be followed.

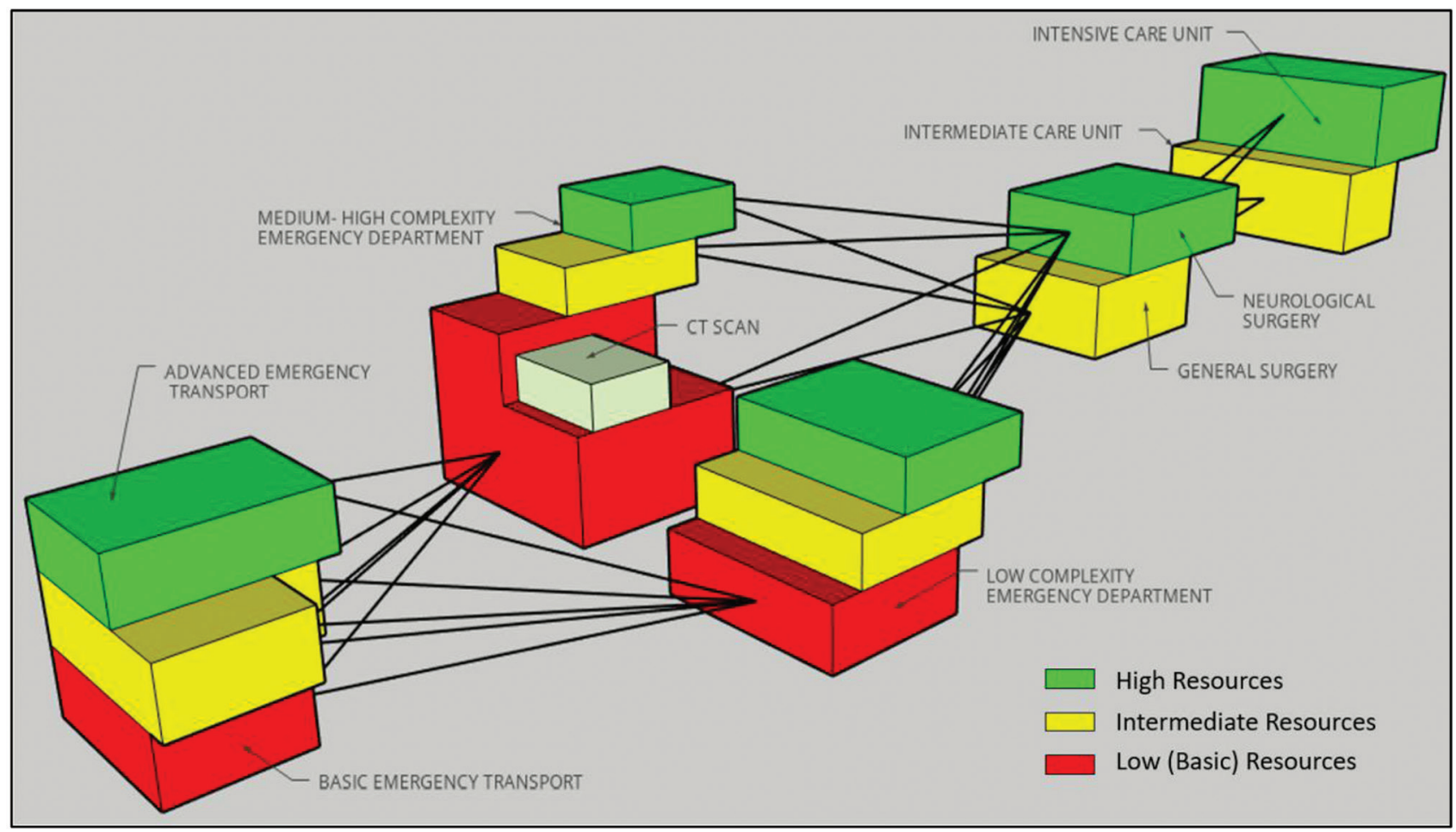

Fig. 1 Three-dimensional stratified scheme according to the level of resources and complexity.

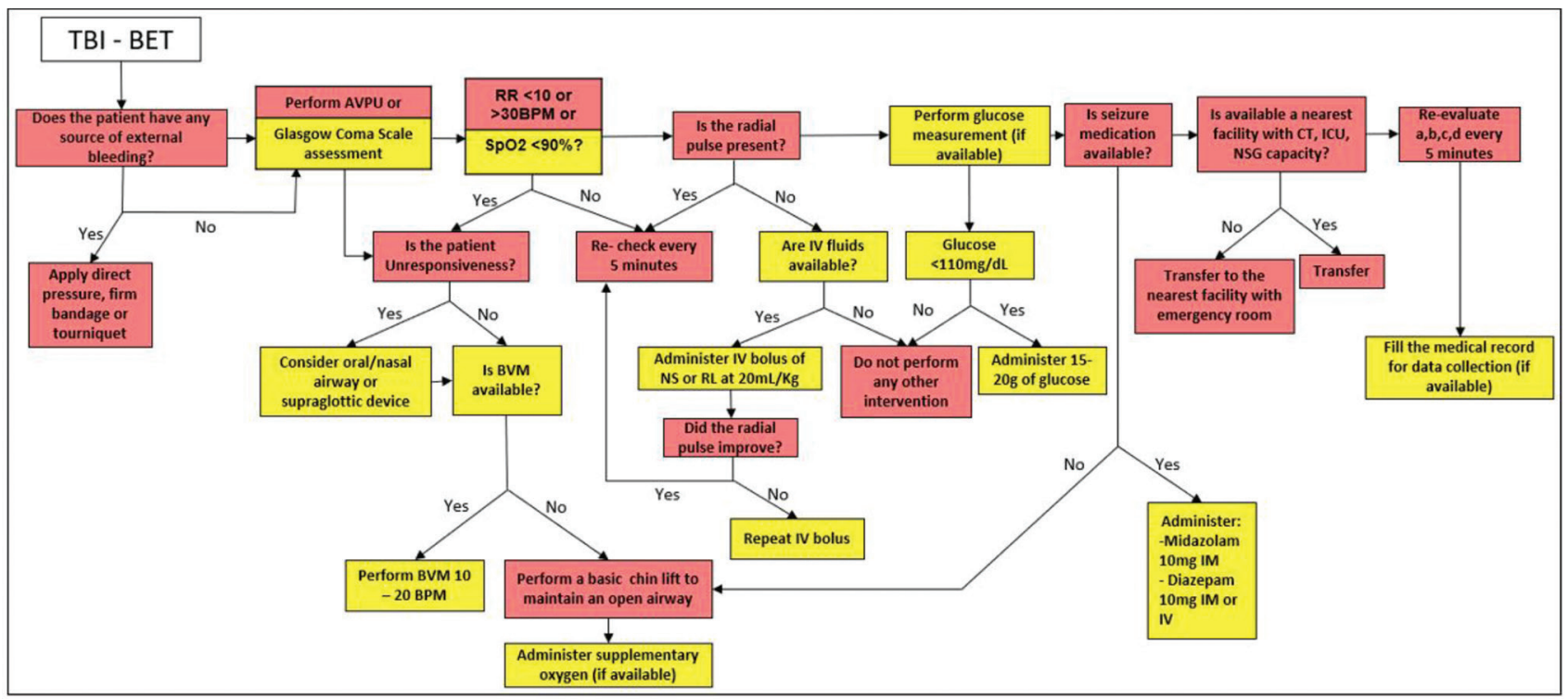

Fig. 2 Management algorithm of the patient with traumatic brain injury (TBI) in basic emergency transport (BET). 
- To determine the requirement for prehospital care and transfer, parameters such as the mechanism of injury, type of injury, clinical status, age, comorbidities, history, and Glasgow coma scale (GCS) should be evaluated.

\section{Questions 3 and 4}

What is the best protocol for treating an adult patient with mild, moderate, or severe TBI in an AET?

\section{Recommendation}

- It is recommended not to remain at the scene for more than 30 minutes, regardless of the patient's clinical status because the time at the scene can diminish the possibility of a good neurological result. The GCS to classify the severity of the injury in the patient should be performed after the initial resuscitation.

- It is recommended to follow the algorithm shown in -Fig. 3, including interventions shown in -Tables 2 and 3.

\section{Question 5}

What is the best protocol for managing an adult patient with mild TBI in a low complexity ED (without CT)?

\section{Recommendation}

- Every mild TBI patient who enters the ED should be treated for any life-threatening event according to the advanced trauma life support (ATLS) primary evaluation, ${ }^{38}$ including those with penetrating injuries to the head. Patients

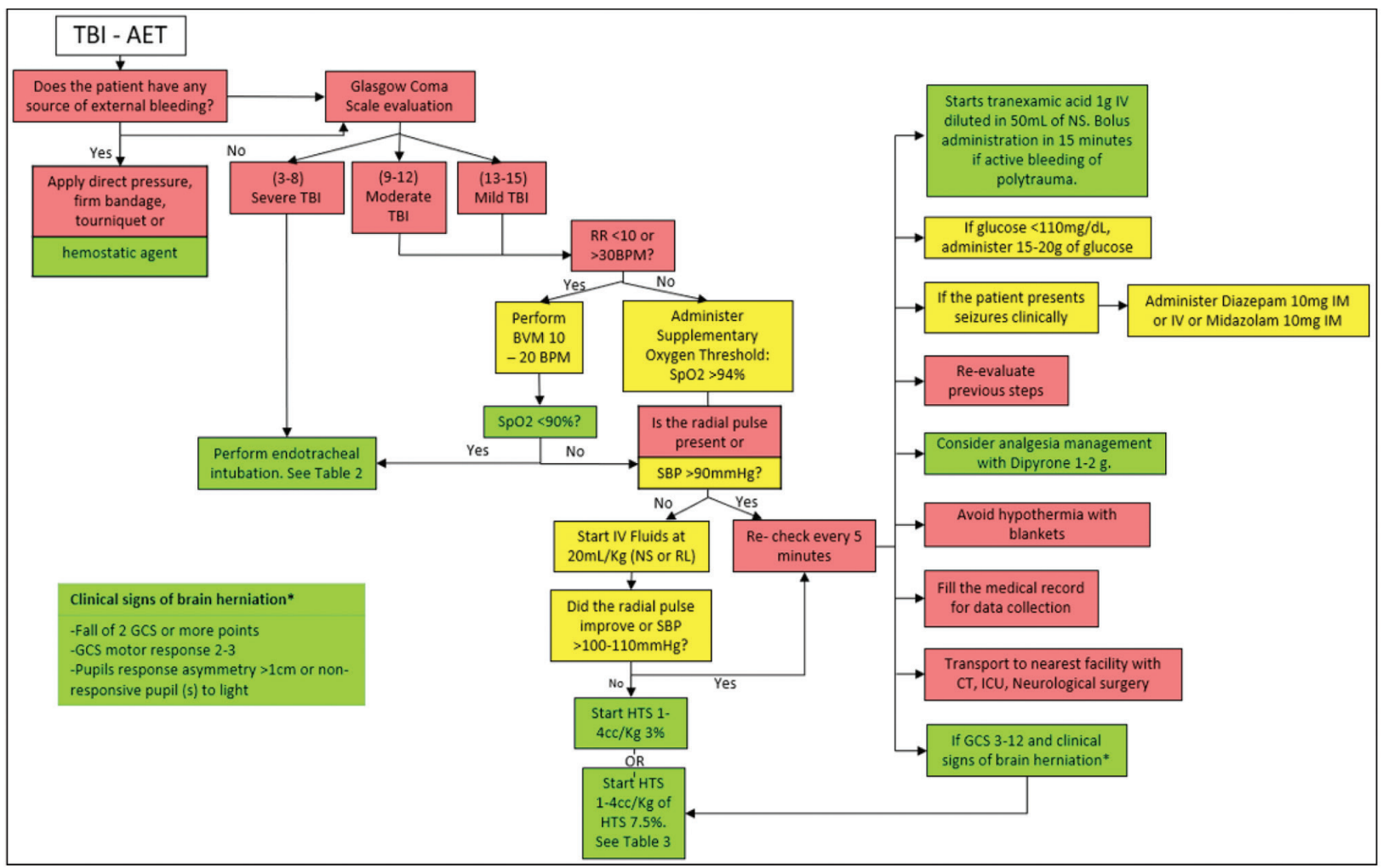

Fig. 3 Management algorithm of the patient with traumatic brain injury (TBI) in advanced emergency transport (AET).

Table 2 Medication sequence for endotracheal intubation

\begin{tabular}{|c|c|c|c|}
\hline Medication & Option 1 & Option 2 & Option 3 \\
\hline Inductors & $\begin{array}{l}\text { Ketamine } \\
\text { Amp } \times 500 \mathrm{mg} \\
\text { Dose: } 1.5-2 \mathrm{mg} / \mathrm{kg} \\
\text { For a patient of } 70 \mathrm{~kg}: 105-140 \mathrm{mg}\end{array}$ & $\begin{array}{l}\text { Midazolam } \\
\text { Amp } \times 5 \mathrm{mg} / \mathrm{amp} \times 15 \mathrm{mg} \\
\text { Dose: } 0.1-0.3 \mathrm{mg} / \mathrm{kg} \\
\text { For a patient of } 70 \mathrm{~kg}: 7-21 \mathrm{mg}\end{array}$ & $\begin{array}{l}\text { Etomidate } \\
\text { Amp } \times 20 \mathrm{mg} \\
\text { Dose: } 0.3 \mathrm{mg} / \mathrm{kg} \\
\text { For a patient of } 70 \mathrm{~kg}=21 \mathrm{mg}\end{array}$ \\
\hline Muscular blockers & $\begin{array}{l}\text { Succinylcholine } \\
\text { Amp } \times 250 \mathrm{mg} \\
\text { Dose: } 1-2 \mathrm{mg} / \mathrm{kg} \\
\text { For a patient of } 70 \mathrm{~kg}=70-140 \mathrm{mg}\end{array}$ & $\begin{array}{l}\text { Rocuronium } \\
\text { Amp } \times 50 \mathrm{mg} \\
\text { Dose: } 0.7-1 \mathrm{mg} / \mathrm{kg} \\
\text { For a patient of } 70 \mathrm{~kg}=50-70 \mathrm{mg}\end{array}$ & $\begin{array}{l}\text { Vecuronium } \\
\text { Amp } \times 50 \mathrm{mg} \\
\text { Dose: } 0.1 \mathrm{mg} / \mathrm{kg} \\
\text { For a patient of } 70 \mathrm{~kg}=7 \mathrm{mg}\end{array}$ \\
\hline Analgesics & $\begin{array}{l}\text { Fentanyl } \\
\text { Amp } \times 500 \mu \mathrm{g} \\
\text { Dose: } 2-4 \mu \mathrm{g} / \mathrm{kg} \\
\text { For a patient of } 70 \mathrm{~kg}=140-280 \mu \mathrm{g}\end{array}$ & $\begin{array}{l}\text { Ketamine } \\
\text { Amp } \times 500 \mathrm{mg} \\
\text { Dose: } 1.5-2 \mathrm{mg} / \mathrm{kg} \\
\text { For a patient of } 70 \mathrm{~kg}=105-140 \mathrm{mg}\end{array}$ & \\
\hline
\end{tabular}

Note: Select any option for each one of the categories according to the availability of medications. 
presenting with a penetrating injury to the head and/or any abnormal finding in the primary clinical evaluation should be referred to a center of high complexity for neuroimaging (see CT reading suggestions at Appendix A in -Supplementary Material S2 [online only]), evaluation by the neurosurgery service, and integrated management according to the criteria in - Tables $\mathbf{4}$ and $\mathbf{5}$ and -Fig. 4.

- If the patient does not have abnormal findings in the primary clinical evaluation, or does not have a penetrating brain injury, or does not meet the referral criteria in - Table 4, the patient should be observed in the ED. After 4 to 6 hours of observation, if the patient does not develop referral criteria (-Table 4 ), consider discharge with recommendations and warning signs.

It is recommended to follow the algorithm shown in - Fig. $\mathbf{5}$.

\section{Questions 6}

What is the best protocol for managing an adult patient with mild TBI in a medium or high complexity ED (with CT scan)?

\section{Recommendation}

- It is recommended that adult patients with mild TBI who enter the ED of medium or high complexity centers complete a comprehensive assessment as described by the ATLS recommendations. ${ }^{38}$

- It is recommended to define neuroimaging requirements according to - Table $\mathbf{4}$, and then perform an interpretation of the $\mathrm{CT}$ as normal or abnormal. If the patient does not meet the criteria for a head CT scan or if the CT is normal, the patient should be observed for 4 to 6 hours, then determine if hospital discharge

Table 5 Suggestions for vasopressor therapy preparation

\begin{tabular}{|l|l|l|}
\hline \multicolumn{2}{|c|}{ Medication } \\
\hline \multirow{3}{*}{$\begin{array}{l}\text { Vasopressor } \\
\text { therapy }\end{array}$} & Noradrenaline & Adrenaline \\
\cline { 2 - 3 } & Amp $\times 4 \mathrm{mg} / 4 \mathrm{~mL}$ & Amp $\times 1 \mathrm{mg} / \mathrm{mL}$ \\
\cline { 2 - 3 } & Dose: & Dose: \\
& $0.05-0.5 \mu \mathrm{g} / \mathrm{kg} / \mathrm{min}$ & $0.1-2 \mu \mathrm{gg} / \mathrm{min}$ \\
\hline
\end{tabular}

Table 3 Suggestions for HTS preparation

\begin{tabular}{|c|c|c|}
\hline \multirow{3}{*}{$\begin{array}{l}\text { Hypertonic } \\
\text { fluids }\end{array}$} & $\begin{array}{l}\text { HTS } 3 \% \\
\text { Peripheral vein }\end{array}$ & $\begin{array}{l}\text { HTS } 7.5 \% \\
\text { Peripheral vein }\end{array}$ \\
\hline & $\begin{array}{l}\text { NS }(0.9 \%) 400 \mathrm{~mL}+\text { sodium chloride ampoules } 100 \mathrm{~mL} \text { (am- } \\
\text { poules of } 20 \mathrm{mEq} \text { in } 10 \mathrm{~mL})\end{array}$ & $\begin{array}{l}\text { NS (0.9\%) } 100 \mathrm{~mL}+\text { sodium chloride ampoules } 150 \\
\mathrm{~mL} \text { (ampoules of } 20 \mathrm{mEq} \text { in } 10 \mathrm{~mL} \text { ) }\end{array}$ \\
\hline & $\begin{array}{l}\text { Dose: } 3-4 \mathrm{~mL} / \mathrm{kg} \\
\text { For a patient of } 70 \mathrm{~kg}=210-280 \mathrm{~mL} \text { per dose } \\
\text { Only for use if SBP }<100 \mathrm{~mm} \text { Hg or clinical signs of brain herni- } \\
\text { ation }\end{array}$ & $\begin{array}{l}\text { Dose: } 2 \mathrm{~mL} / \mathrm{kg} \\
\text { For a patient of } 70 \mathrm{~kg}=140 \mathrm{~mL} \text { per dose } \\
\text { Only for use if SBP }<100 \mathrm{~mm} \mathrm{Hg} \text { or clinical signs of } \\
\text { brain herniation }\end{array}$ \\
\hline
\end{tabular}

Abbreviations: HTS, hypertonic saline; NS, normal saline; SBP, systolic blood pressure.

Table 4 Criteria for transfer of patients with TBI to a high-level facility for neuroimaging or neurosurgical consultation It is recommended that patients with moderate to severe TBI (GCS 3-12) should be transferred immediately to high level of care hospitals with access to neuroimaging and neurosurgery

It is recommended that patients with mild TBI (GCS 13-15) who present one or more of the following criteria be referred for evaluation at an institution that has access to neuroimaging and neurosurgery:

GCS under 15 up to $2 \mathrm{~h}$ after injury

Severe headache

More than two episodes of vomiting

Skull fracture, including depressed fractures or clinical signs of fracture of the skull base (raccoon eyes, retroauricular ecchymosis, otorrhea, or rhinorrhea)

Age older than or equal to $60 \mathrm{y}$

Blurred vision or diplopia

Posttraumatic seizure

Focal neurological deficit

Previous craniotomy

Fall of more than $1.5 \mathrm{~m}$

Retrograde amnesia more than 30 min and/or anterograde amnesia

Suspected intoxication with alcohol and/or psychoactive substances

It is recommended that patients with mild TBI and who are in active treatment with anticoagulants, have active coagulopathies, or are pregnant should be transferred to centers with neurosurgery and neuroimaging services

Abbreviations: GCS, Glasgow coma scale; TBI, traumatic brain injury. 


\section{Immediately after primary \& secondary surveys:}

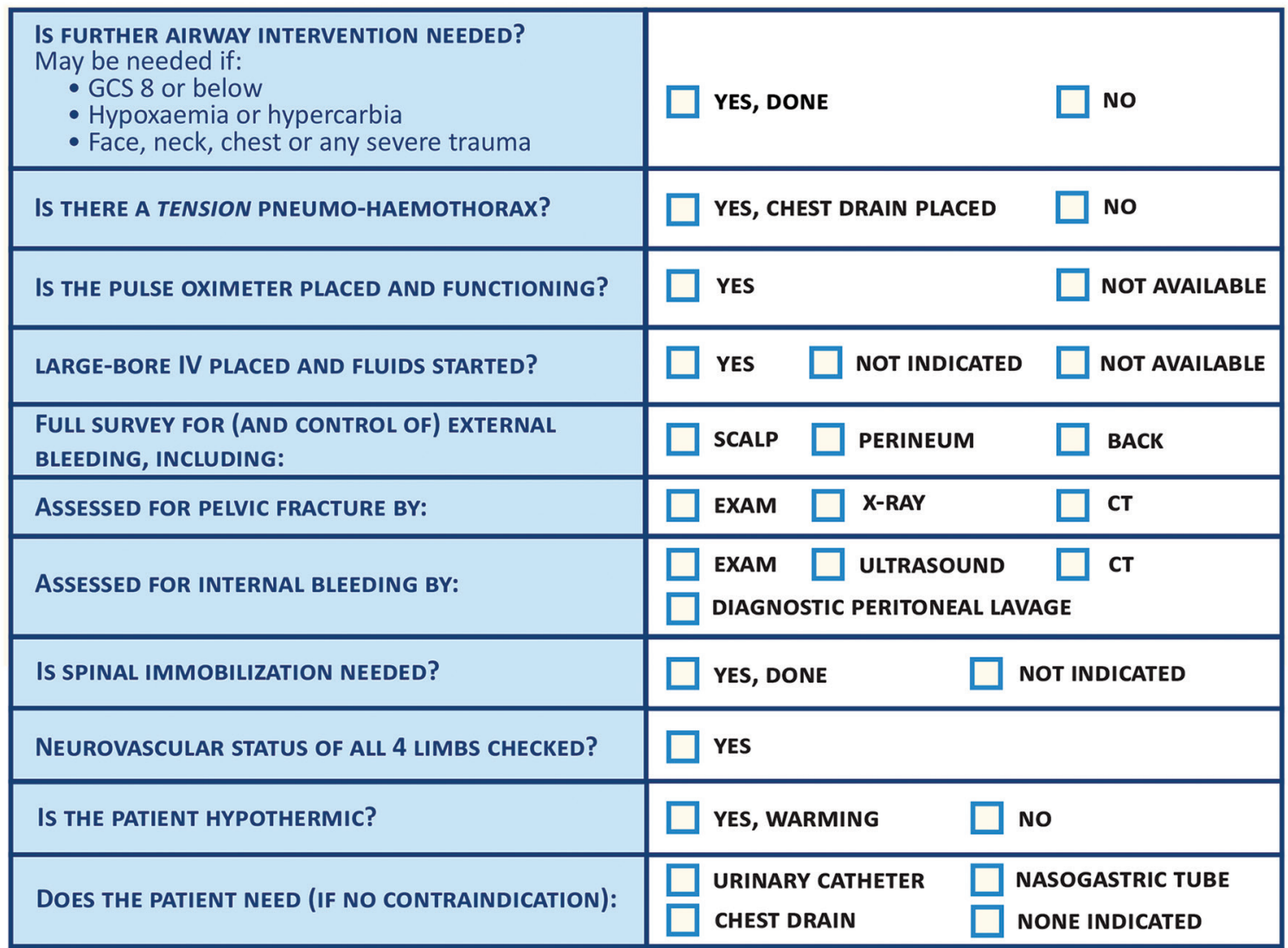

\section{Before team leaves patient:}

\begin{tabular}{|c|c|c|}
\hline HAS THE PATIENT BEEN GIVEN: & $\begin{array}{l}\text { TETANUS VACCINE } \\
\text { ANTIBIOTICS }\end{array}$ & $\begin{array}{l}\text { ANALGESICS } \\
\text { NONE INDICATED }\end{array}$ \\
\hline HAVE ALL TESTS AND IMAGING BEEN REVIEWED? & YES & LOW-UP PLAN IN PLACE \\
\hline WHICH SERIAL EXAMINATIONS ARE NEEDED? & $\begin{array}{l}\text { NEUROLOGICAL } \\
\text { VASCULAR }\end{array}$ & $\begin{array}{l}\text { ABDOMINAL } \\
\text { NONE }\end{array}$ \\
\hline PLAN OF CARE DISCUSSED WITH: & $\begin{array}{l}\text { PATIENT/FAMILY } \\
\text { PRIMARY TEAM }\end{array}$ & $\begin{array}{l}\text { RECEIVING UNIT } \\
\text { OTHER SPECIALISTS }\end{array}$ \\
\hline RELEVANT TRAUMA CHART OR FORM COMPLETED? & YES & NOT AVAILABLE \\
\hline
\end{tabular}

Fig. 4 Trauma Care Checklist. Source: World Health Organization. Available at: https://www.who.int/publications-detail/trauma-care-checklist

with recommendations and warning signs is appropriate. If the CT is abnormal, request an assessment by the neurosurgery service to determine medical or surgical management.

It is recommended to follow the algorithm shown in - Fig. 6.

\section{Question 7}

What is the best protocol for managing an adult patient with moderate to severe TBI in a low complexity ED (without CT)?

\section{Recommendation}

- It is recommended that adult patients with moderate to severe TBI who enter the ED of low complexity centers receive a comprehensive evaluation as described by the ATLS, through primary and secondary evaluation, ${ }^{38}$ and prepare the patient for immediate referral under the best conditions to the nearest center with availability of neurosurgery and neuroimaging as shown in -Fig. 5. 


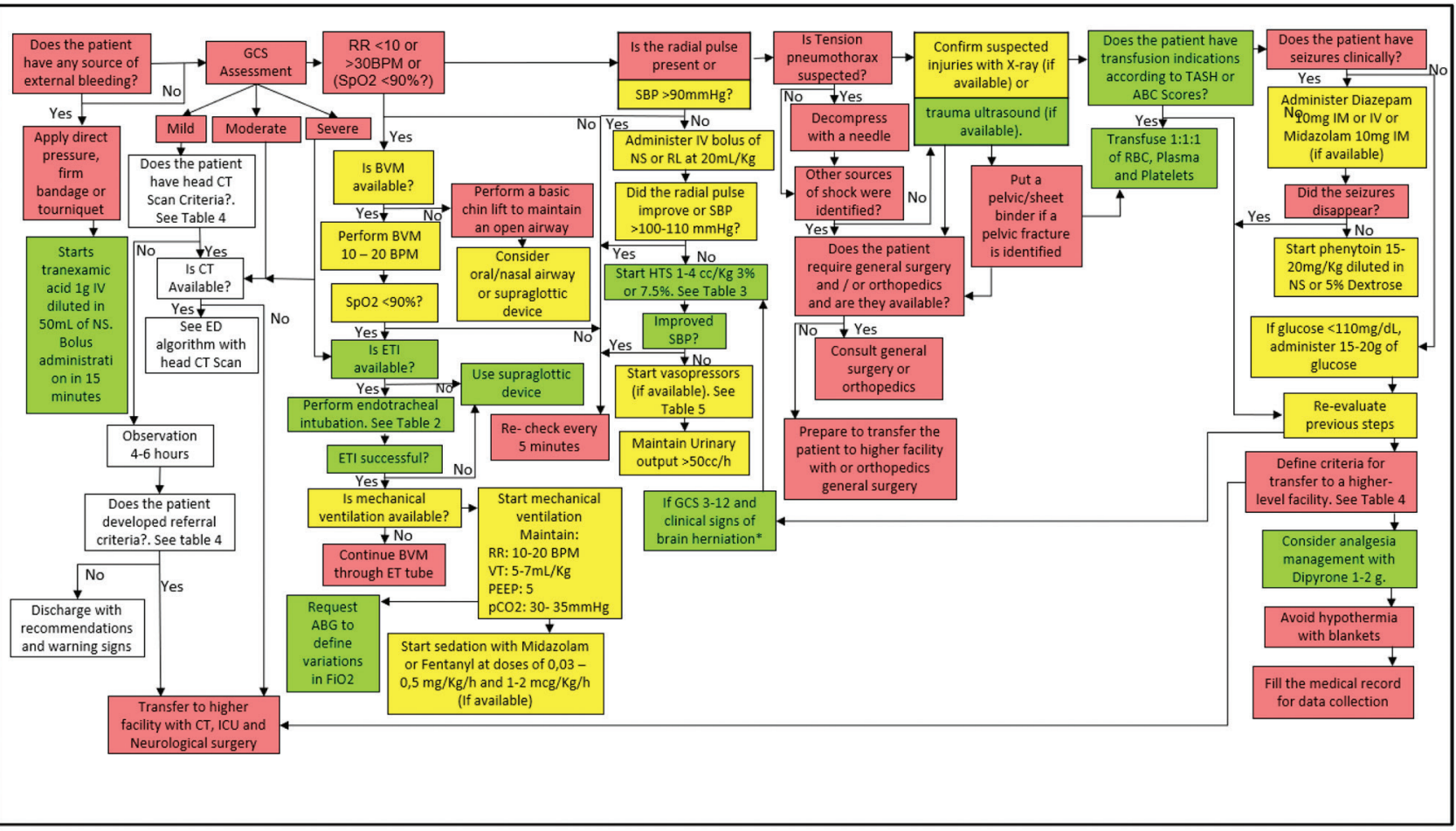

Fig. 5 Management algorithm of the patient with traumatic brain injury (TBI) in a low complexity ED (without CT).

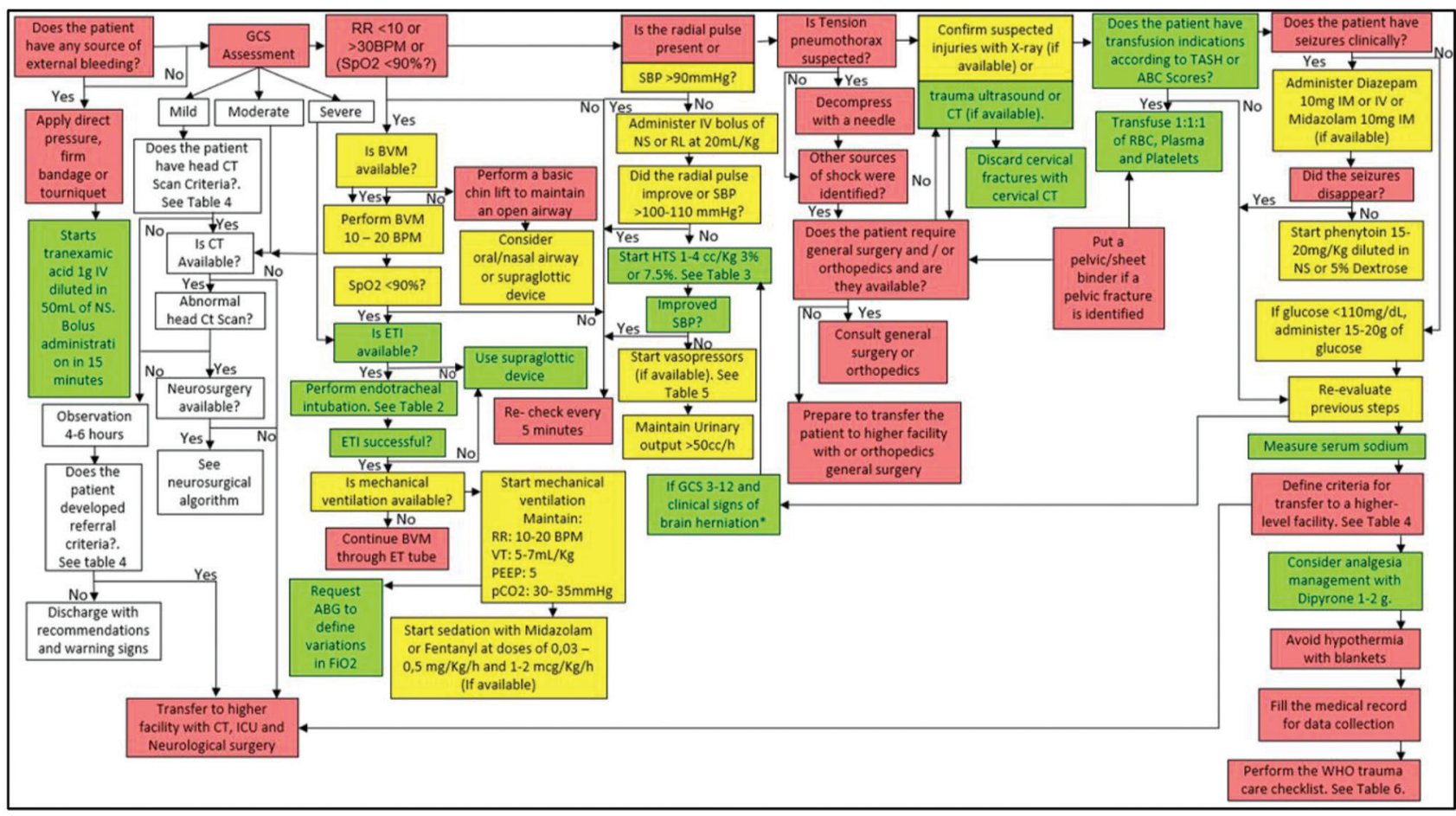

Fig. 6 Management algorithm of the patient with traumatic brain injury (TBI) in a medium or high complexity emergency department (ED) (with computed tomography [CT]).

\section{Question 8}

What is the best protocol for managing an adult patient with moderate to severe TBI in a medium or high complexity ED (with CT scan)?

\section{Recommendation}

- It is recommended to manage an adult patient with moderate to severe TBI in an ED of medium or high complexity, when available. 
It is recommended to follow the algorithm shown in - Fig. 6.

\section{Question 9}

What is the best protocol to determine if a patient with TBI requires immediate surgery?

\section{Recommendation}

- To determine those patients admitted to the ED with TBI that require immediate surgical intervention, the patient must have one or more clinical criteria and one or more imaging criteria (-Table $\mathbf{6}$ ). It is recommended that a neurological examination be performed after adequate resuscitation in the emergency room to determine the clinical criteria.

Table 6 Surgical indications for immediate transfer to a higher level facility with neurosurgery capabilities

\begin{tabular}{|l|l|}
\hline Clinical criteria & Imaging criteria \\
\hline $\begin{array}{l}\text { Pupillary asymmetry with } \\
1 \mathrm{~mm} \text { of difference }\end{array}$ & Midline shift $>5 \mathrm{~mm}$ \\
\hline $\begin{array}{l}\text { GCS motor response of } 4 \text { or } \\
\text { less }\end{array}$ & $\begin{array}{l}\text { Total cisterns compression } \\
\text { (Grade III) }\end{array}$ \\
\hline & $\begin{array}{l}\text { Epidural hematoma } \geq 30 \mathrm{~mL} \text { in } \\
\text { volume }\end{array}$ \\
\hline & $\begin{array}{l}\text { Intracerebral hematoma } \\
\geq 50 \text { mL in volume }\end{array}$ \\
\hline & $\begin{array}{l}\text { Subdural hematoma }>10 \mathrm{~mm} \\
\text { in width }\end{array}$ \\
\hline & $\begin{array}{l}\text { Posterior fossa hematoma with } \\
\text { hydrocephalus }\end{array}$ \\
\hline
\end{tabular}

Abbreviation: GCS, Glasgow coma scale.

Note: One clinical criterion + one imaging criterion = surgical indication. One isolated clinical criterion = medical management.

One isolated imaging criterion = medical management .
- It is suggested that personnel with appropriate training provide strict neurological follow-up to a patient who presents clinical criteria without imaging criteria, or imaging criteria without clinical criteria. Surgery may be indicated in the patient with neurological impairment, defined as a decrease in the GCS of more than 2 points.

Table 7 Criteria for medium-high complexity center for patients with moderate to severe TBI

\begin{tabular}{|l|l|}
\hline Medium complexity & High complexity \\
\hline Hospitalization & Hospitalization \\
\hline $\begin{array}{l}\text { Radiology and diagnostic } \\
\text { imaging, CT scan }\end{array}$ & Surgery \\
\hline $\begin{array}{l}\text { Clinical laboratory, arterial } \\
\text { gases }\end{array}$ & Intensive care \\
\hline Pharmaceutical service & $\begin{array}{l}\text { Intensive neonatal care } \\
\text { (if pediatric center) }\end{array}$ \\
\hline Sterilization process & $\begin{array}{l}\text { Physiotherapy or respiratory } \\
\text { therapy }\end{array}$ \\
\hline Blood transfusion & Pharmaceutical service \\
\hline Pathology & $\begin{array}{l}\text { Radiology and diagnostic } \\
\text { imaging }\end{array}$ \\
\hline Respiratory therapy & Clinical laboratory \\
\hline Nutrition & Blood transfusion \\
\hline Transportation assistance & Hospital support services \\
\hline & Transportation assistance \\
\hline & Sterilization process \\
\hline & Pathology \\
\hline
\end{tabular}

Abbreviations: CT, computed tomography; TBI, traumatic brain injury.

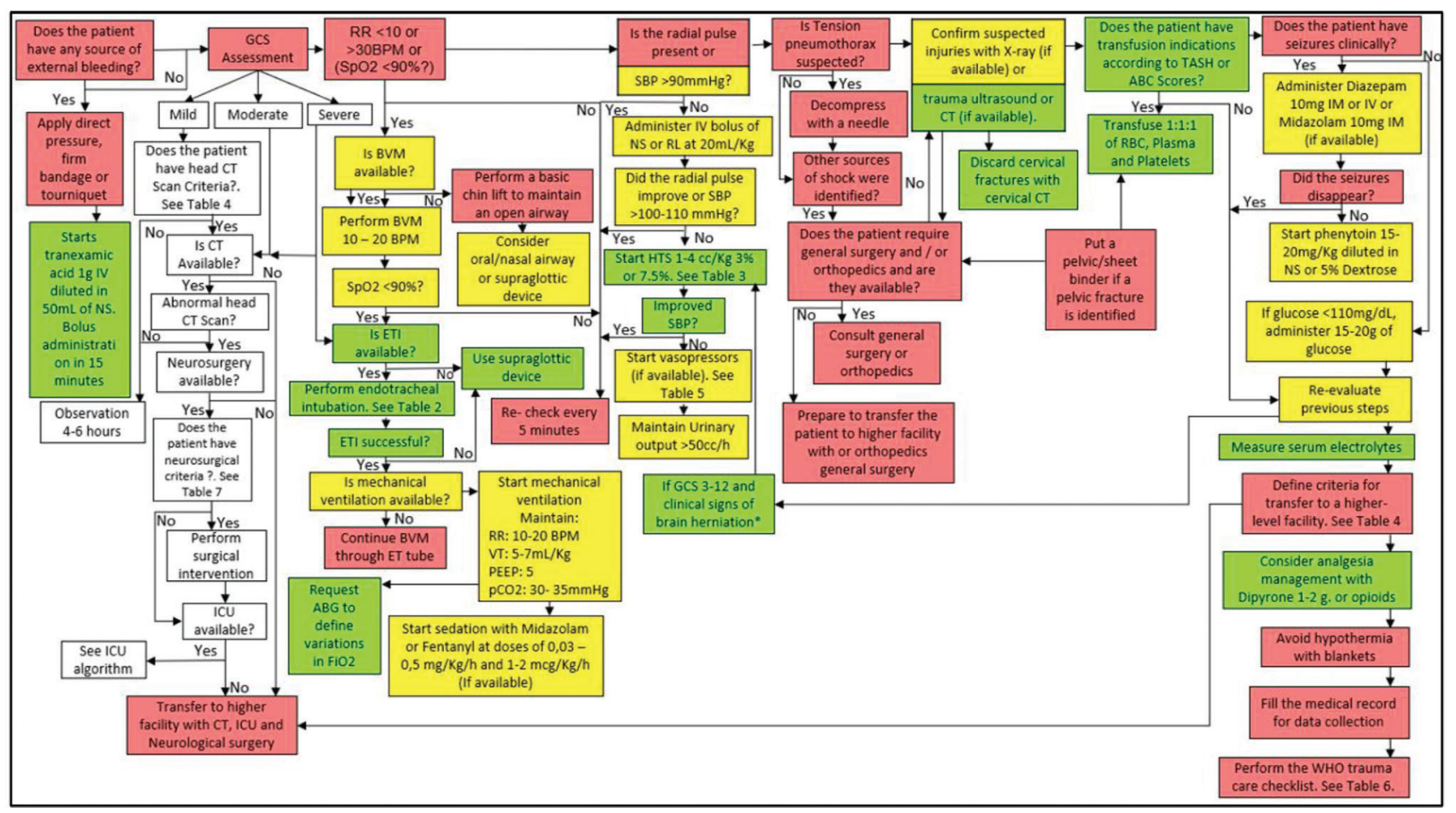

Fig. 7 Management algorithm of patient with traumatic brain injury (TBI) who requires immediate surgery. 
- Finally, it is suggested that patients who, after adequate resuscitation, have bilateral mydriasis and a score of 3 on the GCS, should be assessed by the neurosurgeon to determine whether to perform a quick surgical procedure or not.

\section{Question 10}

What is the best protocol to manage a patient who requires immediate surgery in a health care facility that does not have neurosurgery?

\section{Recommendation}

- Many hospitals in low-resource settings do not have a neurosurgery service; those located in remote rural areas. It is recommended that close communication occurs between the lower level facility and the referral site to ensure appropriate management during the transportation of patients who will undergo surgery to avoid secondary complications ( - Table 7 ).

It is recommended to follow the algorithm shown in $\boldsymbol{\bullet}$ Fig. $\mathbf{7}$.

\section{Question 11}

What is the best protocol to manage a patient who requires immediate surgery in a medical center that has neurosurgery but no ICU?

Table 8 Richmond agitation-sedation scale (RASS)

\begin{tabular}{|c|c|}
\hline $\begin{array}{l}\text { Target } \\
\text { RASS }\end{array}$ & RASS description \\
\hline+4 & Combative, violent, danger to staff \\
\hline+3 & Pulls or removes tube(s) or catheters; aggressive \\
\hline+2 & $\begin{array}{l}\text { Frequent non purposeful movement, fights } \\
\text { ventilator }\end{array}$ \\
\hline+1 & Anxious, apprehensive, but not aggressive \\
\hline 0 & Alert and calm \\
\hline-1 & Awakens to voice (eye opening/contact) > $10 \mathrm{~s}$ \\
\hline-2 & $\begin{array}{l}\text { Light sedation, briefly awakens to voice } \\
\text { (eye opening/contact) }<10 \mathrm{~s}\end{array}$ \\
\hline-3 & $\begin{array}{l}\text { Moderate sedation, movement, or eye opening. } \\
\text { No eye contact }\end{array}$ \\
\hline-4 & $\begin{array}{l}\text { Deep sedation, no response to voice, but move- } \\
\text { ment or eye opening to physical stimulation }\end{array}$ \\
\hline-5 & $\begin{array}{l}\text { Unarousable, no response to voice, or physical } \\
\text { stimulation }\end{array}$ \\
\hline
\end{tabular}

Table 9 Criteria for admission to the ICU

\begin{tabular}{|l|}
\hline GCS: $\leq 12$ with or spinal cord injury \\
\hline ICU support for any other system \\
\hline Planned trauma surgery urgent ( $24 \mathrm{~h})$ \\
\hline $\begin{array}{l}\text { Comorbidities: (anticoagulated patients, liver failure, chronic } \\
\text { kidney disease in dialysis, heart failure, epilepsy, or who are being } \\
\text { treated with ASA/clopidogrel) }\end{array}$ \\
\hline
\end{tabular}

Abbreviations: ICU, intensive care unit; GCS, Glasgow coma scale.

\section{Recommendation}

- It is recommended to perform surgery for a patient with TBI that meets the criteria for immediate surgery (-Table 6) in the context of a hospital that has a neurosurgery service and anesthesiologist but does not have an ICU. During the immediate postoperative period, a referral to a medical center with an ICU should be requested. If such a center is available, the patient should be transported immediately. If not, the patient should be maintained with mechanical ventila-

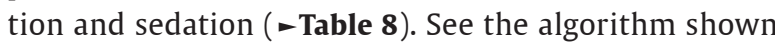
in -Fig. 7 .

\section{Question 12}

What is the best protocol to manage a patient with moderate to severe TBI in service of intermediate care (no ICU) in a health care center of medium complexity?

Table 10 Management objectives in medium complexity center Maintain oxygenation with saturation more than $90 \%, \mathrm{PaO}_{2}$ more than 60

Maintain $\mathrm{PaCO}_{2}$ in normal parameters for age and height above sea level

Keep lactate levels less than $2 \mathrm{mmol} / \mathrm{L}$

Maintain systolic blood pressure $\geq 100 \mathrm{~mm} \mathrm{Hg}$ in patients between 50 and 60 years of age, or 110 or more for patients aged 15 to 49 or older than $70 y$

Keep heart rate at normal levels (60-90 bpm)

Monitor the appearance of seizures without prophylactic treatment

Evaluate the neurological condition of the patient, if there is a Glasgow coma scale change of more than 2 points, it is recommended to perform an image evaluation

Maintain glucose levels between 110 and $170 \mathrm{mg} / \mathrm{dL}$ to avoid hypoglycemia

Keep temperature between 36 and $37.5^{\circ} \mathrm{C}$ is suggested to not perform prophylactic or therapeutic hypothermia, if there is spontaneous hypothermia do not perform active rewarming. Ensure that the patient is in regulated normothermia

Keep sodium levels between 135 and $155 \mathrm{mmol} / \mathrm{L}$

Maintain normal levels of other electrolytes

Maintain normal levels of coagulation tests: INR less than 1.5, platelets more than $100,000 /$ UL and fibrinogen more than $150 \mathrm{mg}$

Maintain hemoglobin above $9 \mathrm{~g} / \mathrm{dL}$

Initiate orally intake early according to tolerance and check for contraindications

Initiate mechanical thromboprophylaxis in the first $24 \mathrm{~h}$ and pharmacological prophylaxis after $24 \mathrm{~h}$ if there are no hemorrhagic lesions and after $48 \mathrm{~h}$ if the hemorrhagic lesions are stable in the CT scan

Evaluation and rehabilitation according to the patient condition in the first $48 \mathrm{~h}$

Abbreviations: CT, computed tomography; INR, international normalized ratio. 


\section{Recommendation}

- It is recommended that the management of adult patients with moderate to severe TBI takes place in a medium complexity care center that has intermediate care if it does not meet ICU criteria (see - Table 9). The criteria to determine a center of medium complexity are shown in - Table 10.

- All patients who are hospitalized in intermediate care in medium complexity centers should be monitored for evaluation and management with an emphasis on the prevention of secondary injury and the progress of the primary lesion. For this purpose, target maintenance of parameters is shown in -Tables $\mathbf{1 0}$ and $\mathbf{1 1}$.

It is recommended to follow the algorithm shown in $\boldsymbol{- F i g . ~} \mathbf{8}$.

\section{Question 13}

What is the best protocol to manage a patient with moderate to severe TBI in an ICU within a center of medium-high complexity?

\section{Recommendation}

- It is recommended that the management of adult patients with moderate to severe TBI in a medium-high complexity health care center be performed in the ICU if it meets the established criteria shown in - Table 7 (see Supplementary Material S1, Algorithm 10 [online only]).

- Specialized medical personnel should carry out the management of such a patient with the availability of face-to-face neurosurgeon consultation.

Table 11 Minimum monitoring-patient with moderate TBI

\begin{tabular}{|l|}
\hline Cardioscope, pulse oximeter, MAP \\
\hline Arterial blood gas \\
\hline Follow GCS, pupil reactivity, and motor deficit every hour \\
\hline Follow vital signs every hour \\
\hline Monitoring the temperature by the axillary route and every hour \\
\hline Glycemia monitoring every $8 \mathrm{~h}$ \\
\hline Monitoring daily sodium except if it has osmotic therapy or dysnatremias. In this case, it needs to be monitoring more often \\
\hline Monitoring of K, Mg, Cl daily or at the doctor's discretion \\
\hline Monitoring of PT, PTT, fibrinogen, platelets should be repeated if they are altered according to medical criteria \\
\hline Monitoring hemoglobin levels every day \\
\hline
\end{tabular}

Abbreviations: GCS, Glasgow coma scale; MAP, mean arterial pressure; PT, prothrombin time; PTT, partial thromboplastin time; TBI, traumatic brain injury.

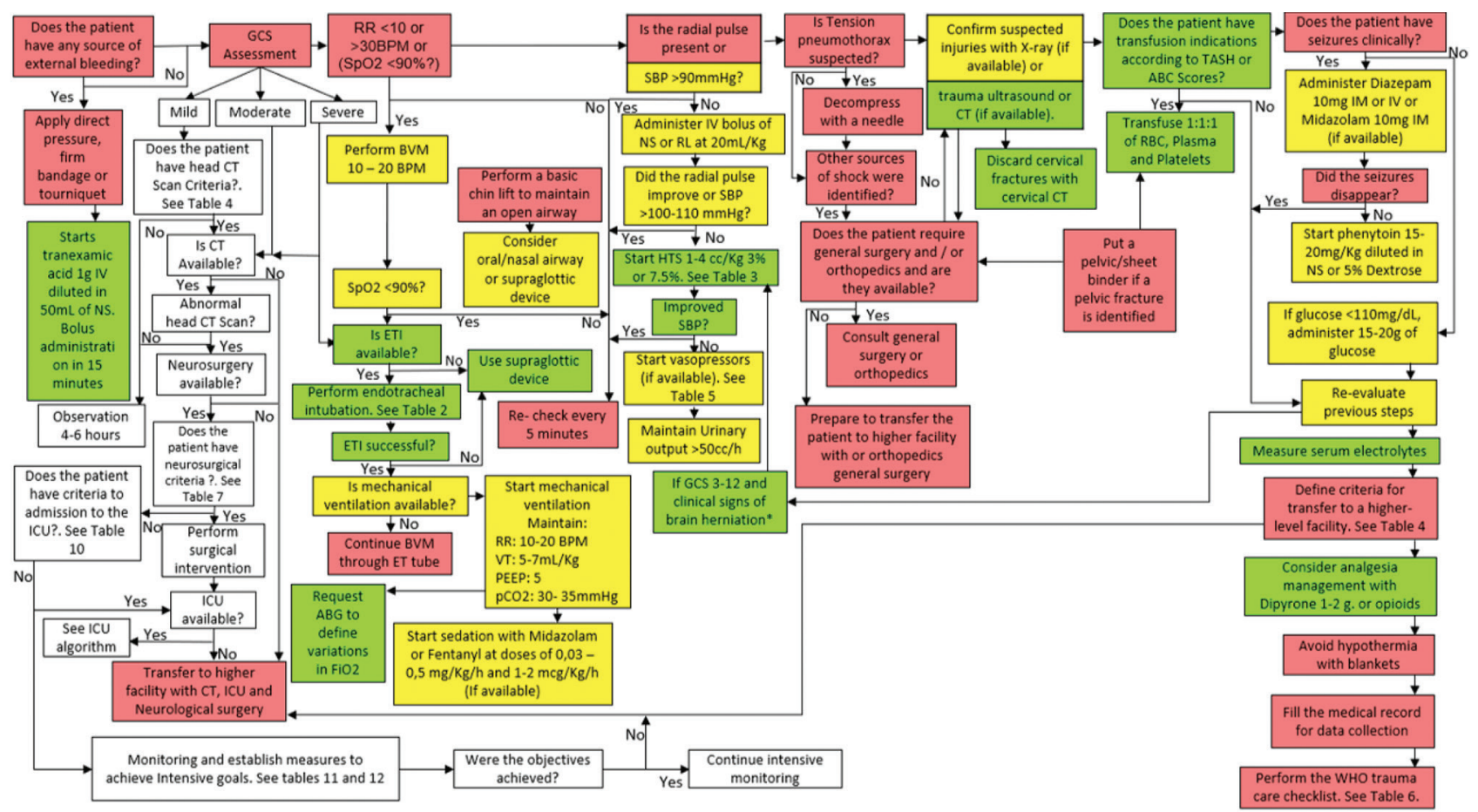

Fig. 8 Management algorithm of patient with moderate to severe traumatic brain injury (TBI) in service of intermediate care. 
Table 12 Patient monitoring in the ICU

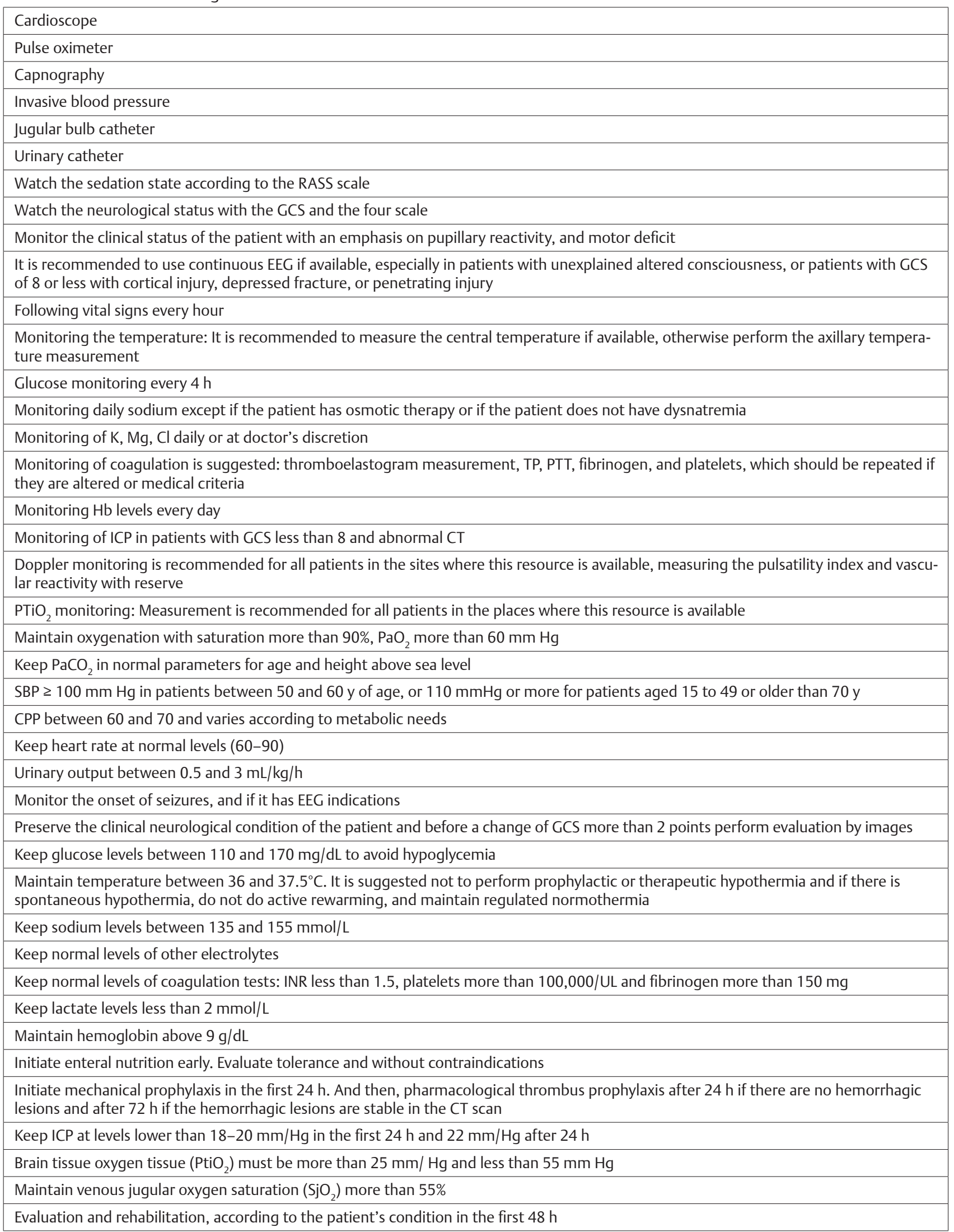

Abbreviations: CT, computed tomography; GCS, Glasgow coma scale; ICP, intracranial pressure; INR, international normalized ratio; RASS, Richmond agitation-sedation scale; TBI, traumatic brain injury. 
- When the patient arrives in the ICU, they should evaluate: complete medical record with emphasis on physical, neurological, and paraclinical exams performed so far; verify oxygenation status, hemodynamic status, and presence of other injured organs, especially cervical spine injury; and additionally to perform identification, prevention, and management of secondary injury (-Table 12) (see -Supplementary Material S1, Algorithm 10 [online only]).

- The management of the patient in the ICU should emphasize the prevention of secondary injury and the prevention of the progress of the primary injury, for which the patient should be monitored, with a target to maintain the parameters according to the proposed criteria (-Tables 9-11) (see Supplementary Material S1-S3, Appendix B [online only]).

\section{Discussion}

Current evidence-based guidelines for the treatment of TBI were generated from studies conducted in developed countries. ${ }^{15-32,39}$ It is estimated that $80 \%$ of the global population live in developing economies ${ }^{40}$ in which access to resources required for optimum treatment is limited. There are few guidelines focused on the management of TBI in low and middle income countries with organized international methodology. ${ }^{8,34}$ Most of these guidelines, developed in high and low-middle income countries do not fill the gaps of different scenarios in real-life situations due to the methodology itself, attached to the evidence-based methodological science. ${ }^{40-44}$ In real circumstances, not all the resources are always available on time, especially in LMICs. ${ }^{45}$ The present effort is focused on filling these gaps with a mixed methods approach combining evidence-based recommendations and expert opinion where there is no evidence-based medicine to develop helpful recommendations for real-life situations in different context with resources level variation. The BOOTStraP is two dimensional. The first dimension is the treatment phase (prehospital care, ED, surgery, and ICU). The second dimension is the level of resources. Resource availability in LMICs is ever-changing. Even a high-resource center can find itself without enough medications, or with a sudden loss of personnel. Furthermore, one system may have enough resources in one treatment phase (e.g., ED) but insufficient resources in another (e.g., emergency transport). While the two-dimensional categorization in - Fig. $\mathbf{1}$ is over-simplified, it illustrates the territory, and we attempted to cover with the stratified treatment options of BOOTStraP (Supplementary Material S1, available online only).

The strength of this project includes the participation of experts from different specialties since they contribute to connecting the guidelines between the different dimensions. On the contrary, the color teaching material makes it easier for interested people to apply the recommendations according to the context in which they are.

Limitations of this project are the noninclusion of patients younger than 15 years, therapies or tools undergoing experimentation, and the direct nonadvocacy of primary prevention and the rehabilitation process since they were outside the scope of this consensus.

Future steps for this project will include (1) to disseminate BOOTStraP globally, performing an external validation of the exercise by an international group of experts, with the support of international collaborators such as the World Federation of Neurosurgical Societies, the WHO, and the Global Health Research Group on Neurotrauma from the United Kingdom and (2) to conduct a study to measure its influence on outcomes for patients with TBI in low-resource environments. ${ }^{46,47,51}$

BOOTStraP is intended to be a practical handbook for care providers to use to treat patients with TBI whatever resources are available. BOOTStraP is an attempt to provide treatment options to $80 \%$ of the world's population, in regions of LMICs economies, where disparities in health care resources and workforce exist daily, challenging the application of guidelines and protocols developed for HICs. ${ }^{51}$

\section{Conclusion}

Current evidence-based recommendations of the guidelines for the treatment of TBI are generated with significant flaws in aspects where evidence does not exist or is limited. Knowledge transferability of these recommendations to practice generates critical disconnection from real scenarios were training, or resources are limited. Development of expert consensus-based recommendations, even for areas were training or resources are weak or absent, is possible using validated methodologies. Stratification of recommendations for interventions according to the availability of the resources on different stages of integral care is a proposed method for filling gaps in actual evidence, to organize a better strategy for interventions in different real-life scenarios. We develop 10 algorithms of management for building TBI protocols based on expert consensus to articulate treatment options in prehospital care, EDs, neurological surgery, and intensive care, independent of the level of availability of resources for care.

\section{Note}

No human subjects were involved in this work.

\section{Authors' Contributions}

Andrés M. Rubiano, MD, PhD(c): Principal investigator, senior author.

David S. Vera, MD, José N. Carreño, MD, Oscar Gutiérrez, MD, Jorge Mejía, MD, MSc, Juan D. Ciro, MD, Ninel D. Barrios, MD, Alvaro R. Soto, MD, Paola A. Tejada, MD, MSC, PhD, Maria C. Zerpa, MD, Alejandro Gómez, TAPH, MD, Norberto Navarrete, MD, MSc, Oscar Echeverry, TAPH, Mauricio Umaña, MD, Claudia M. Restrepo, MD, José L. Castillo, MD, Oscar A. Sanabria, MD, Maria P. Bravo, MD, Claudia M. Gómez, MD, Daniel A. Godoy, MD, German D. Orjuela, TAPH, Augusto A. Arias, MD, Raul A. Echeverri, MD, Jorge Paraños, MD: Coinvestigators, coauthors.

Jorge H. Montenegro, MD, Nancy Ann Carney, PhD, and Angelica Clavijo MD: Coninvestigators, coauthors also. 


\section{Funding}

The National Institute for Health Research (NIHR) Global Health Research Group on Neurotrauma is supporting Dr. Rubiano research work. The group was commissioned by the NIHR using Official Development Assistance funding (project 16/137/105). The views expressed in this article are those of the authors and are not necessarily those of the UK National Health Service, NIHR, or the UK Department of Health.

\section{Conflict of Interest}

None declared.

\section{References}

1 Global Burden of Disease Study 2013 Collaborators. Global, regional, and national incidence, prevalence, and years lived with disability for 301 acute and chronic diseases and injuries in 188 countries, 1990-2013: a systematic analysis for the Global Burden of Disease Study 2013. Lancet 2015;386(9995):743-800

2 Dewan MC, Rattani A, Gupta S, et al. Estimating the global incidence of traumatic brain injury. J Neurosurg 2018;0(4):1-18

3 Jarman MP, Castillo RC, Carlini AR, Kodadek LM, Haider AH. Rural risk: geographic disparities in trauma mortality. Surgery 2016;160(6):1551-1559

4 Tiesman H, Young T, Torner JC, McMahon M, Peek-Asa C, Fiedler J. Effects of a rural trauma system on traumatic brain injuries. J Neurotrauma 2007;24(7):1189-1197

5 Brown JB, Kheng M, Carney NA, Rubiano AM, Puyana JC. Geographical disparity and traumatic brain injury in America: rural areas suffer poorer outcomes. J Neurosci Rural Pract 2019;10(1):10-15

6 World Health Organization. Violence and Injury Prevention, Global status report on road safety 2015. Available at: https://www.who. int/violence_injury_prevention/road_safety_status/2015/en/. Accessed November 30, 2018

7 Colombian Institute of Forensic Sciences and Legal Medicine. Forensic. Data for Life. 2018. Available at: http:// www.medicinalegal.gov.co/documents/20143/262076/ Forensis+2017+Interactivo.pdf/0a09fedb-f5e8-11f8-71ed2d3b475e9b82. Accessed November 30, 2018

8 Colombia. Ministry of Health and Social Protection, Colciencias, MEDITECH Foundation. Clinical Practice Guideline for the diagnosis and treatment of adult patients with severe Traumatic Brain Injury. GSSSH - 2014. Available at: http://gpc.minsalud. gov.co/gpc_sites/Repositorio/Conv_563/GPC_trauma_craneo/ CPG_TBI_professionals.pdf. Accessed November 30, 2018

9 Colombian Ministry of Health, Resolution 3100 of 2019. Available at: https://www.minsalud.gov.co/sites/rid/Lists/BibliotecaDigital/RIDE/DE/DIJ/resolucion-3100-de-2019.pdf

10 MockC, Lormand JD, Goosen J,Joshipura M, Peden M. Guidelines for essential trauma care. Geneva, World Health Organization, 2004 Available at: https://www.who.int/violence_injury_prevention/ publications/services/guidelines_traumacare/en/

11 Jaeschke R, Guyatt GH, Dellinger P, et al; GRADE Working Group. Use of GRADE grid to reach decisions on clinical practice guidelines when consensus is elusive. BMJ 2008;337:a744

12 Thangaratinam S, Redman C. The Delphi technique. Obstet Gynecol 2005;7:120-125

13 Allen J, Dyas J, Jones M. Building consensus in health care: a guide to using the nominal group technique. $\mathrm{Br} \mathrm{J}$ Community Nurs 2004;9(3):110-114

14 Marshall S, Bayley M, McCullagh S, Velikonja D, Berrigan L. Clinical practice guidelines for mild traumatic brain injury and persistent symptoms. Can Fam Physician 2012;58(3):257-267
15 Potapov A, Krylov V, Gavrilov A, et al. Guidelines for the management of severe traumatic brain injury. Part 1. Organization of neutrauma-care system and diagnosis. Guidelines for practitioners. Zh Vopr Neirokhir Im N Burdenko 2015;79(6):86-91

16 Potapov AA, Krylov VV, Gavrilov AG, et al. [Guidelines for the diagnosis and treatment of severe traumatic brain injury. Part 2. Intensive care and neuromonitoring]. Vopr Neirokhir 2016;80(1):98-106

17 Potapov AA, Krylov VV, Gavrilov AG, et al. [Guidelines for the management of severe traumatic brain injury. Part 3. Surgical management of severe traumatic brain injury (options)]. Vopr Neirokhir 2016;80(2):93-101

18 Ontario Neurotrauma Foundation, Guidelines for Concussion/ Mild Traumatic Brain Injury \& Persistent Symptoms, 3rd ed. 2013:1-163. Ottawa: Ontario Neurotrauma Foundation

19 Chesnut RM, Bleck TP, Citerio G, et al. A consensus-based interpretation of the benchmark evidence from South American trials: treatment of intracranial pressure trial. J Neurotrauma 2015;32(22):1722-1724

20 Le Roux P, Menon DK, Citerio G, et al; Neurocritical Care Society; European Society of Intensive Care Medicine. Consensus summary statement of the International Multidisciplinary Consensus Conference on Multimodality Monitoring in Neurocritical Care: a statement for healthcare professionals from the Neurocritical Care Society and the European Society of Intensive Care Medicine. Intensive Care Med 2014;40(9):1189-1209

21 Andrews PJ, Citerio G, Longhi L, Polderman K, Sahuquillo J, Vajkoczy P; Neuro-Intensive Care and Emergency Medicine (NICEM) Section of the European Society of Intensive Care Medicine. NICEM consensus on neurological monitoring in acute neurological disease. Intensive Care Med 2008;34(8):1362-1370

22 Stocchetti N, Picetti E, Berardino M, et al. Clinical applications of intracranial pressure monitoring in traumatic brain injury: report of the Milan consensus conference. Acta Neurochir (Wien) 2014;156(8):1615-1622

23 Claassen J, Taccone FS, Horn P, Holtkamp M, Stocchetti N, Oddo M; Neurointensive Care Section of the European Society of Intensive Care Medicine. Recommendations on the use of EEG monitoring in critically ill patients: consensus statement from the neurointensive care section of the ESICM. Intensive Care Med 2013;39(8):1337-1351

24 Figaji A, Puppo C; Participants in the International Multidisciplinary Consensus Conference on Multimodality Monitoring. Multimodality monitoring consensus statement: monitoring in emerging economies. Neurocrit Care 2014;21(Suppl 2): S239-S269

25 Le Roux P, Menon DK, Citerio G, et al. The International Multidisciplinary Consensus Conference on Multimodality Monitoring in Neurocritical Care: a list of recommendations and additional conclusions: a statement for healthcare professionals from the Neurocritical Care Society and the European Society of Intensive Care Medicine. Neurocrit Care 2014;21(2, suppl 2):S282-S296

26 Bullock R, Chesnut R, Ghajar J, et al. Guidelines for the surgical management of traumatic brain injury. Neurosurgery 2006;58(3):1-111

27 Newcombe R, Merry G. The management of acute neurotrauma in rural and remote locations: A set of guidelines for the care of head and spinal injuries. J Clin Neurosci. 1999;6(1):85-93

28 Badjatia N, Carney N, Crocco TJ, et al. Guidelines for prehospital management of traumatic brain injury, 2nd edition. Prehosp Emerg Care 2008;12(suppl 1) :S1-52

29 Carney N, Totten AM, O'Reilly C, et al. Guidelines for the management of severe traumatic brain injury, 4th edition. Neurosurgery 2017;80(1):6-15

30 Le Roux P, Menon DK, Citerio G, et al; Neurocritical Care Society; European Society of Intensive Care Medicine. Consensus 
summary statement of the International Multidisciplinary Consensus Conference on Multimodality Monitoring in Neurocritical Care : a statement for healthcare professionals from the Neurocritical Care Society and the European Society of Intensive Care Medicine. Intensive Care Med 2014;40(9):1189-1209

31 American College of Surgeons Committee on Trauma. ACS TQIP best practices in the management of traumatic brain injury. Chicago: American College of Surgeons. Available at: https:// www.facs.org/-/media/files/quality-programs/trauma/ tqip/tbi_guidelines.ashxReleased January 2015. Accessed November 30, 2018

32 Stevens RD, Shoykhet M, Cadena R. Emergency Neurological Life Support: intracranial hypertension and herniation. Neurocrit Care 2015;23(suppl 2) :S76-S82

33 Garvin R, Mangat HS. Emergency Neurological Life Support: severe traumatic brain injury. Neurocrit Care 2017;27(suppl 1) :159-169

34 Srivastava A, Stake A, Devi BI, et al. Traumatic brain injury-multi organizational consensus recommendations for India. 2017;1(78). Available at: http://ntsi.co.in/wp-content/ uploads/2017/11/Version.pdf. Accessed November 30, 2018

35 World Health Organization. The WHO Trauma Care Checklist. Available at: https://www.who.int/emergencycare/publications/trauma-care-checklist.pdf. Accessed November 30, 2018

36 Alvis-Miranda HR, Navas C, Villa-Delgado R, Rubiano AM, Alcala-Cerra G, Moscote-Salazar LR. Trends in management of traumatic brain injury by emergency physicians in Colombia. Panam J Trauma Crit Care Emerg Surg 2013;2(3):134-138

37 Moscote LR, Lugo CM, Castellar S, Alcala G, Puyana JC, Rubiano AM. Trends in neurosurgical management of traumatic brain injury in Colombia. Panam J Trauma Crit Care Emerg Surg 2014;3(1):23-28

38 ATLS SubcommitteeAmerican College of Surgeons' Committee on TraumaInternational ATLS working group. Advanced trauma life support (ATLS): the ninth edition. J Trauma Acute Care Surg 2013;74(5):1363-1366

39 Carney N, Totten AM, O'Reilly C, et al. Guidelines for the management of severe traumatic brain injury, fourth edition. Neurosurgery $2017 ; 80(1): 6-15$

40 Cnossen MC, Scholten AC, Lingsma HF, et al. Adherence to guidelines in adult patients with traumatic brain injury: a living systematic review. J Neurotrauma 2016; J Neurotrauma, 2016: 33:1-14

41 Dawes AJ, Sacks GD, Cryer HG, et al; Los Angeles County Trauma Consortium. Compliance with evidence-based guidelines and interhospital variation in mortality for patients with severe traumatic brain injury. JAMA Surg 2015;150(10):965-972
42 Khormi YH, Gosadi I, Campbell S, Senthilselvan A, O’Kelly C, Zygun D. Adherence to brain trauma foundation guidelines for management of traumatic brain injury patients and its effect on outcomes: systematic review. J Neurotrauma 2018;35(13):1407-1418

43 Hirschi R, Rommel C, Letsinger J, Nirula R, Hawryluk GWJ. Brain Trauma Foundation guideline compliance: results of a multidisciplinary, international survey. World Neurosurg 2018;116:e399-e405

44 Gupta D, Sharma D, Kannan N, et al. Guideline adherence and outcomes in severe adult traumatic brain injury for the CHIRAG (Collaborative Head Injury and Guidelines) study. World Neurosurg 2016;89:169-179

45 Ramesh A, Fezeu F, Fidele B, et al. Challenges and solutions for traumatic brain injury management in a resource-limited environment: example of a public referral hospital in Rwanda. Cureus 2014;6(5):e179

46 United Nations Conference on Trade and Development (UNCTAD), Population. In: United Nations, Handbook of Statistics 2018, Geneva, 2018. Available at: https://unctad.org/en/ PublicationsLibrary/tdstat43_en.pdf

47 Kolias AG, Rubiano AM, Figaji A, Servadei F, Hutchinson PJ. Traumatic brain injury: global collaboration for a global challenge. Lancet Neurol 2019;18(2):136-137

48 Park KB. Editorial. Research in global neurosurgery: informing the path to achieving neurosurgical equity. J Neurosurg 2019;130(4):1053-1054

49 Dewan MC, Rattani A, Fieggen G, et al; We would like to thank the following individuals for their dedication and contribution to identifying the global neurosurgical deficit. Collaborators are listed in alphabetical order; Executive Summary of the Global Neurosurgery Initiative at the Program in Global Surgery and Social Change. Global neurosurgery: the current capacity and deficit in the provision of essential neurosurgical care. J Neurosurg 2018; $\cdots \bullet: 1-10$

50 Reynolds TA, Sawe H, Rubiano AM, Shin SD, Wallis L, Mock $\mathrm{CN}$. Strengthening health systems to provide emergency care. In: Jamison DT, Gelband H, Horton S, Jha P, Laxminarayan R, Mock CN, Nugent R, eds. Disease Control Priorities: Improving Health and Reducing Poverty, 3rd ed. Chap 13. Washington (DC): The International Bank for Reconstruction and Development/The World Bank; 2017

51 Corley J, Lepard J, Barthélemy E, Ashby JL, Park KB. Essential neurosurgical workforce needed to address neurotrauma in low- and middle-income countries. World Neurosurg 2019;123:295-299 